\title{
Low subcutaneous degradation and slow absorption of insulin in insulin-dependent diabetic patients during continuous subcutaneous insulin infusion at basal rate
}

\author{
D. J.Chisholm, E. W. Kraegen, M.J. Hewett and S. Furler \\ The Garven Institute of Medical Research, St. Vincent's Hospital, Darlinghurst, NSW, Australia
}

Summary. As information on the absorption kinetics and local degradation of infused insulin is relevant to programming strategies for continuous subcutaneous insulin infusion, we examined the time relationship of systemic insulin appearance and quantitated subcutaneous degradation during a near-basal rate of continuous subcutaneous insulin infusion in five insulin-dependent diabetic patients. Plasma free insulin was monitored for $8 \mathrm{~h}$ during and $3 \mathrm{~h}$ after a subcutaneous (abdominal wall) infusion of neutral insulin at $2.4 \mathrm{U} / \mathrm{h}$. An identical intravenous infusion $(2-4 \mathrm{~h})$ was given on a separate occasion. Plateau levels of free insulin were not significantly different during the subcutaneous $(37 \pm 8 \mathrm{mU} / \mathrm{l})$ and intravenous $(40 \pm 7 \mathrm{mU} / 1)$ infusions. Fitting of the free insulin data to our two-pool model of the subcutaneous space gave a mean estimate of 9.2 units insulin ( $=3.8 \mathrm{~h}$ infusion) for the subcutaneous depot after $8 \mathrm{~h}$. Model estimates of systemic insulin appearance, as a percentage of subcutaneous infusion rate, were $59 \%$ and $93 \%$ after 4 and $8 \mathrm{~h}$ respectively, and $76 \% 2 \mathrm{~h}$ after cessation of infusion. In insulin-dependent diabetic patients subcutaneous degradation of infused insulin is negligible but local accumulation in the subcutaneous space is considerable. The delay in absorption has important clinical implications for interruption and resumption of continuous subcutaneous insulin infusion and also for programming of variable basal rates.

Key words: Continuous subcutaneous insulin infusion, insulin absorption, local insulin degradation, free insulin.
Continuous subcutaneous insulin infusion (CSII) is now widely used for the treatment of insulin-dependent diabetes. Meal increments are usually given as a bolus or square wave and the basal rate may be constant or varied during a 24 -h period [1]. We have published previously data indicating that simulation of the normal insulin response to meals requires very rapid delivery of the meal increment [2]. With regard to the basal delivery rate, information is required as to loss of insulin by local subcutaneous degradation, the amount accumulated in the subcutaneous (SC) space before vascular entry and the time delay before entry to the vascular system.

We have previously studied normal subjects and have developed a model of SC absorption kinetics [3]. In this study, the investigations have been extended to insulin-dependent diabetes and the previously-developed kinetic model has been used to interpret the data.

\section{Subjects and methods}

\section{Subjects}

Five insulin-dependent diabetic patients (three male, two female) were studied on two occasions. The duration of diabetes was
$0.5-42$ years; age range $26-57$ years; weight $82-130 \%$ of ideal body weight. Three of the subjects had no C-peptide response to stimulation and were being treated by CSII because of erratic blood glucose control on conventional therapy. Insulin dosage ranged from $21-46 \mathrm{U} /$ day (mean $37 \mathrm{U} /$ day). Subjects sat quietly in an air-conditioned environment $\left(22^{\circ} \mathrm{C}\right.$ ) with an intravenous (IV) cannula inserted in an antecubital vein for blood sampling. Patients took neutral insulin during the preceding day and, except for one subject who had only an evening dose of neutral insulin, were infused with insulin overnight by the same route (IV or SC) as that used for the study. The two subjects with endogenous insulin were fasted for $8 \mathrm{~h}$ before the IV study. All studies had prior approval by the St Vincent's Hospital Research and Ethics Committee and all subjects studied gave informed consent after a detailed explanation of the study.

\section{Intravenous study}

An additional IV cannula was inserted in the contralateral arm for infusion of highly purified porcine insulin (Velosulin U100, Nordisk) for 120-240 min. Previous studies suggested that $120 \mathrm{~min}$ was sufficient to produce plateau insulin levels $[4,5]$. However in three subjects the infusion was continued for $240 \mathrm{~min}$ to ensure that the free insulin levels at $2 \mathrm{~h}(43 \pm 12.7 \mathrm{mU} / 1)$ were not less than those during a more prolonged infusion $(42 \pm 13.7 \mathrm{mU} / 1)$. Thus the free insulin level at $2 \mathrm{~h}$ has been taken as the plateau level for all subjects. The insulin was diluted $(54 \mathrm{U} / 500 \mathrm{ml})$ in polygeline solution (Haemaccel, Hoechst-Behringwerke, Marburg, FRG) [6] to give a delivery rate of $2.4 \mathrm{U} / \mathrm{h}$ using a servo-controlled peristaltic pump (Model 531, Ivac Corporation, 


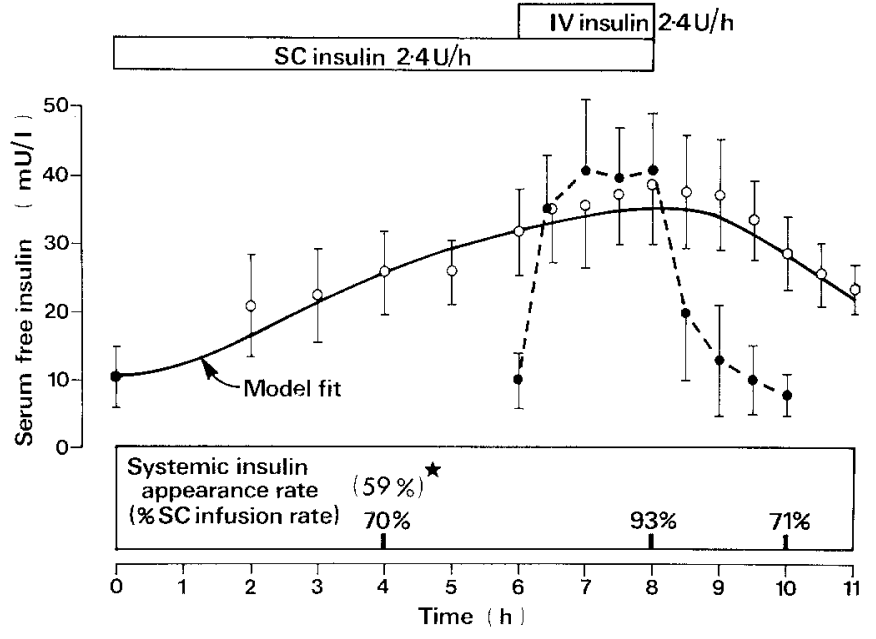

Fig. 1. Serum free-insulin levels in response to SC infusion for $8 \mathrm{~h}$ (O) or IV infusion for $2 \mathrm{~h}(\mathbf{0})$. The free-insulin levels at time 0 for SC infusion are extrapolated from samples taken on a separate day. The solid line $(-)$ represents the curve derived from the mathematical model. The lower panel indicates the calculated systemic appearance at 4,8 and $10 \mathrm{~h}$ for the SC infusion. * The figure of $70 \%$ systemic appearance would include some contribution from insulin infused prior to time 0 . The figure of $59 \%$ is an estimate of the systemic appearance rate if this contribution is removed

San Diego, California, USA) in combination with a microdrip set (60 drops/ml, Metriset V1428, McGaw, New Zealand). The coefficient of variation in volume flow using several drip sets was estimated to be $2.5 \%$. Samples were taken for blood glucose, serum free insulin and serum C-peptide at 30 -min intervals.

\section{Subcutaneous study}

A 25 -gauge scalp-vein needle was inserted into the anterior abdominal wall for a constant infusion of insulin (from the same batch as that used for the IV study) from a 2-ml syringe using an infusion pump (Harvard Instruments, Millis, Mass, USA). The rate of insulin delivery was identical to that in the IV study at $2.4 \mathrm{U} / \mathrm{h}$ with a nominal volume flow of $60 \mu \mathrm{l} / \mathrm{h}$ (actual rate $59.3 \mu \mathrm{l} / \mathrm{h}$, coefficient of variation $6 \%$ ). The duration of infusion was $8 \mathrm{~h}$. As the insulin levels produced by the infusion in the first $2 \mathrm{~h}$ were not required for interpretation of the data, and to avoid prolonged fasting, subjects were instructed to commence the insulin infusion using a preloaded Auto Syringe AS6C pump (Auto Syringe, Hookset, New Hampshire, USA) and to have breakfast at $07.00 \mathrm{~h}$. The subjects came to the Institute at $08.30 \mathrm{~h}$ where the AS6C pump was replaced by the Harvard pump (without displacing the scalp vein needle or interrupting the infusion) and blood sampling was commenced at $120 \mathrm{~min}$ from the start of the infusion. Samples were taken hourly for serum free insulin and C-peptide and half-hourly for blood glucose estimation.

In the subjects with undetectable C-peptide, blood glucose was not precisely controlled, though a dextrose infusion was used to keep the blood glucose level $>3 \mathrm{mmol} / 1$. In the two subjects with C-peptide, care was taken to ensure a relatively low blood glucose level (between 3 and $5 \mathrm{mmol} / \mathrm{l}$ ) at the time of plateau insulin determination so that this determination would not be significantly influenced by endogenous insulin; C-peptide levels were $<0.2 \mu \mathrm{g} / 1$ in these subjects at cessation of the IV and SC infusions, and $<0.3 \mu \mathrm{g} / 1$ between the fourth and eighth hours of SC infusion.

\section{Laboratory assays}

Serum free-insulin levels were determined using a radioimmunoassay with second-antibody separation after initial treatment of the serum with polyethylene glycol to remove insulin antibodies [7]. In all cases serum was tested for specific $\mathrm{I}^{125}$-insulin-binding after polyethylene glycol treatment, and binding was not detected. Serum C-peptide was assayed by radioimmunoassay using the agents supplied by Novo Research Institute, Denmark [8], and blood glucose by an immobilised enzyme method (Model 23 AM glucose analyzer, Yellow Springs Instruments, Yellow Springs, Ohio).

\section{Mathematical model and statistical analysis}

A model including a two-pool SC compartment provides a good description of the absorption process in normal subjects [3]. First-order rate constants describe the movement of insulin between the two SC pools $\left(\mathrm{k}_{12}\right)$ and from the second pool into the plasma $\left(\mathrm{k}_{\mathrm{sp}}\right)$. A further rate constant describes degradation or irreversible binding of insulin in the two SC pools $\left(\mathrm{k}_{\mathrm{D}}\right)$. A single pool is assumed for the plasma space. The dynamics of the insulin in this pool are defined by the distribution volume $\left(V_{D}\right)$ and the metabolic clearance rate which were determined by a least-squares fit to the IV infusion data. These parameters were then held constant while a least-squares fit of the SC data was performed to determine the parameters $\mathrm{k}_{12}, \mathrm{k}_{\mathrm{sp}}$ and $\mathrm{k}_{\mathrm{D}}$. The differential equations describing the model were solved numerically using a fourth order Runge-Kutta technique. Fits to experimental data were obtained from a non-linear regression program MODFIT [9]. All calculations were performed on a PDP-11/10 computer. A basal sample was not obtained before commencement of the SC study, so basal free insulin levels obtained on a separate day, after overnight infusion at the same rate, were used (Fig. 1). It should be noted that even substantial variations in this basal estimation have very little influence on the calculated systemic appearance rate at $8 \mathrm{~h}$.

Estimates of the rate of entry of insulin into the plasma and of the size of the SC depot of insulin were obtained directly from the model behaviour with "best-fit" model parameters. Estimates of the errors in these two functions were obtained from a sensitivity analysis of model behaviour to small changes in model parameters. The coefficients of variation in model parameters were calculated by the MODFIT program from the residual variance of the fitted model behaviour about the mean data. Thus the coefficient of variation represents the certainty with which mean behaviour can be predicted rather than indicating subject-to-subject variation.

Statistical comparisons were performed using a paired Student's t-test. Data are expressed as mean $\pm S E M$, except where otherwise indicated.

\section{Results}

During IV infusion, free-insulin levels rose rapidly in the first $30 \mathrm{~min}$ and reached a plateau between 60 and $120 \mathrm{~min}(40 \pm 8 \mathrm{mU} / 1$ at $120 \mathrm{~min})$. Following cessation of IV infusion mean free-insulin levels declined rapidly to $48 \%$ of the plateau level within $30 \mathrm{~min}$ (Fig. 1). In contrast, $\mathrm{SC}$ insulin caused a gradual elevation of serum free insulin levels until a plateau was approached between 6 and $8 \mathrm{~h}$. The plateau free-insulin level during the SC infusion ( $37 \pm 8 \mathrm{mU} / 1)$ was $93 \%$ of, and not significantly different from, that achieved by the IV infu$\operatorname{sion}(40 \pm 7 \mathrm{mU} / 1)$. In no subject did plateau insulin levels for IV and SC infusion differ by $>5 \mathrm{mU} / 1$. Stopping the $\mathrm{SC}$ infusion resulted in a gradual decline so that the mean free-insulin level $3 \mathrm{~h}$ later was still $62 \%$ of the plateau level.

Figure 1 includes a curve derived from the mathematical model compared with the recorded free-insulin data (see Methods and [3]) and estimates of the systemic 
appearance rate during the $\mathrm{SC}$ infusion. The model indicates a substantial accumulation of insulin in the SC space, i.e. 9.2 units (coefficient of variation $7 \%$ ), the amount of infusion over $3.8 \mathrm{~h}$, at the end of the $8 \mathrm{~h} \mathrm{SC}$ infusion. After $4 \mathrm{~h}$ of SC infusion the systemic appearance rate of insulin was $70 \%$ (coefficient of variation $8 \%$ ) of the infusion rate and after $8 \mathrm{~h}$ it was $93 \%$ (coefficient of variation $10 \%$ ). In keeping with substantial SC accumulation the systemic appearance rate fell by only $24 \%$ (to $71 \%$ of the infusion rate, coefficient of variation $10 \%) 2 \mathrm{~h}$ after cessation of the SC infusion. It should be noted that the systemic appearance rate of $70 \%$ at $4 \mathrm{~h}$ includes a contribution from the $\mathrm{SC}$ infusion before the start of the study. To correct for this, a simulation was performed of the systemic appearance resulting from the same model constants derived from the experimental data, but assuming no previous insulin infusion and zero free-insulin levels at time 0 . This resulted in an estimated systemic appearance rate of $59 \%$ at $4 \mathrm{~h}$ but did not influence estimated systemic appearance at 8 or $10 \mathrm{~h}$. The result at $4 \mathrm{~h}$ is more in keeping with the estimation (50\%) in normal subjects [3].

\section{Discussion}

There is very little information on the pharmacokinetics of insulin infused SC $[10,11]$, in contrast to SC injection [12-18]. Furthermore studies performed by examining disappearance of radioactivity (from labelled insulin) from a SC injection site [12] do not allow distinction between absorption into the systemic circulation and local degradation.

We have compared the kinetics of systemic appearance of insulin during SC and during IV infusions. Results from the IV study allowed calculation for each subject of the metabolic clearance rate of insulin and hence of the systemic delivery rate during $\mathrm{SC}$ infusion [3]. The infusion rate of $2.4 \mathrm{U} / \mathrm{h}$, approximately double the usual basal rate during CSII $(0.5-1.5 \mathrm{U} / \mathrm{h})$, was used to reduce the effect of errors in insulin assay; the model and our previous studies indicate that the results would have been very similar had a lower infusion rate been used.

The results indicate that the kinetics of absorption of SC-infused insulin in insulin-dependent diabetic subjects do not differ substantially from those in normal subjects $[3,5]$. The finding that the plateau free-insulin level after prolonged SC infusion is $93 \%$ of that from IV infusion indicates that local SC degradation is very small. The opposite conclusion was reached in a similar study of SC and IV infusions [19], but it is now clear that the low plasma insulin levels observed after SC infusion for only $2 \mathrm{~h}$ were related to delayed absorption rather than reduction in bioavailability. While individual diabetic subjects with insulin resistance due to SC degradation have been described [20], this is probably a rare idiosyncratic response and not simply an exaggeration of a general phenomenon in insulin-dependent diabetes.

The slow kinetics shown by these studies have several important clinical implications. First, interruption of CSII will not usually result in a rapid decline in free insulin levels; thus there would be a 'safety margin' of $2-3 \mathrm{~h}[21,22]$ though a rapid deterioration in the metabolic state may then occur [22]. Secondly, CSII should be initiated or resumed with a bolus dose (or temporarily augmented basal rate) to prevent a period of insulin deficiency, such as may have contributed to episodes of ketoacidosis reported in diabetic patients on CSII [23, 24]. Thirdly, some manufacturers of pumps for CSII are incorporating sophisticated programming capabilities for basal delivery; it must be noted that a change in the pump delivery rate will take several hours to cause a substantial alteration of systemic insulin delivery.

CSII is a valuable new option in insulin therapy. However, its intelligent and appropriate use obviously depends on an understanding of the kinetics of insulin delivery to the systemic circulation.

Acknowledgement. This study was supported by a grant from the National Health and Medical Research Council of Australia.

\section{References}

1. Felig P, Bergman M (1982) Intensive ambulatory treatment of insulin-dependent diabetes. Ann Intern Med 97: 225-230

2. Chisholm DJ, Kraegen EW, Zelenka GS (1981) Programming of insulin delivery with meals during subcutaneous insulin infusion. Diabetes Care 4: 265-268

3. Kraegen EW, Chisholm DJ (1984) Insulin responses to varying profiles of subcutaneous insulin infusion: kinetic modelling studies. Diabetologia 26: 208-213

4. Campbell LV, Kraegen EW, Meler H, Lazarus L (1979) Hormonal responses to insulin infusion in diabetes mellitus. Diabetologia $16: 359-364$

5. Kraegen EW, Chisholm DJ, Hewett MJ (1983) Comparison of plateau insulin levels achieved by intravenous or subcutaneous insulin infusion: evidence for low rates of subcutaneous degradation. Diabetes Care 6: 118-121

6. Kraegen EW, Lazarus L, Meler H, Campbell LV, Chia YO (1979) Hormonal responses to insulin infusion in diabetes mellitus. Diabetologia 16: 359-364

7. Desbuquois B, Aubach GD (1971) Use of polyethylene glycol to separate free and antibody-bound peptide hormones in radioimmunoassays. J Clin Endocrinol Metab 33: 732-738

8. Heding LG (1975) Radioimmunological determinations of human C-peptide in serum. Diabetologia 11: 541-548

9. McIntosh JEA, McIntosh RP (1980) Mathematical modelling and computers in endocrinology. Springer, Berlin Heidelberg New York

10. Kobayashi T, Sawano S, Itoh T, Kosaka K, Hirayama H, Kasuya $Y(1983)$ The pharmacokinetics of insulin after continuous subcutaneous infusion or bolus subcutaneous injection in diabetic patients. Diabetes 32: 331-336

11. Lauritzen T, Pramming S, Deckert T, Binder C (1983) Pharmacokinetics of continuous subcutaneous insulin infusion. Diabetologia $24: 326-329$

12. Binder C (1969) Absorption of injected insulin. Acta Pharmacol Toxicol (Copenh) 27 (Suppl 2): 1-84

13. Stevenson RW, Tsakok TI, Parsons JA (1980) Matched glucose responses to insulin administered subcutaneously and intravenous- 
1y. Evidence for subcutaneous inactivation of insulin. Diabetologia $18: 423-426$

14. Berger M, Halban PA, Müller WA, Offord RE, Renold AE, Vranic M (1978) Mobilization of subcutaneously injected tritiated insulin in rats: effects of muscular exercise. Diabetologia 15: 133-140

15. Berger M, Halban PA, Girardier L, Seydoux J, Offord RE, Renold AE (1979) Absorption kinetics of subcutaneously injected insulin. Evidence for degradation at the injection site. Diabetologia 17: 97-99

16. Duckworth WC, Kitabchi AE (1981) Insulin metabolism and degradation. Endocr Rev 2: 210-232

17. Guerra SO, Kitabchi AE (1976) Comparison of the effectiveness of various routes of insulin injection: insulin levels and glucose response in normal subjects. J Clin Endocrinol Metab 42: 869-874

18. Owens DR, Jones MK, Hayes TM, Heding LG, Alberti KGMM, Home PD, Burrin JM (1981) Comparative study of subcutaneous, intramuscular and intravenous administration of human insulin. Lancet 2: 118-121

19. Waldhäusl WK, Bratusch-Marrain PR, Vierhapper H, Nowotny $P$ (1983) Insulin pharmacokinetics following continuous infusion and bolus injection of regular porcine and human insulin in healthy man. Metabolism 32: 478-485

20. Friedenberg GR, White N, Cataland S, O'Dousio TM, Sofos JF, Santiago JV (1981) Diabetes responsive to intravenous but not subcutaneous insulin: effectiveness of aprotinin. N Engl J Med $305: 363-368$
21. Keller U, Schnell H, Sonnenberg GE, Gerber PPG, Stauffacher W (1983) Role of glucagon in enhancing ketone body production in ketotic diabetic man. Diabetes 32: 387-391

22. Krzentowski G, Scheen A, Castillo M, Luyckz AS, Lefebvre PJ (1983) A 6-hour nocturnal interruption of a continuous subcutaneous insulin infusion: 1 . Metabolic and hormonal consequences and scheme for a prompt return to adequate control. Diabetologia 24: $314-318$

23. Mecklenburg R, Sannar C, Becker N, Benson J, Benson E, Brazel P, Fredlund P, Metz R, Nielsen R (1983) Frequency of complications associated with insulin pump therapy: report of experience with 198 patients. Diabetes 32 [Suppl 1] $35 \mathrm{~A}$

24. Peden NR, McKendry JBR, Braaten JT (1983) Acute uncontrolled diabetes during long term subcutaneous insulin infusion. Diabetes 32 [Suppl 1] $36 \mathrm{~A}$

Received: 16 August 1983

and in revised form: 4 June 1984

Dr. D.J.Chisholm

The Garvan Institute of Medical Research

St Vincent's Hospital

Darlinghurst

NSW, Australia 